\title{
Library Classification Systems and Organization of Islamic Knowledge
}

\section{Current Global Scenario and Optimal Solution}

\section{Haroon Idrees}

Standard library classification systems like Dewey Decimal Classification (DDC), U.S. Library of Congress Classification (LCC), and Universal Decimal Classification (UDC) are internationally known and widely used by libraries as the tools for organizing information. Charles Ammi Cutter's Expansive Classification (EC), James Duff Brown's Subject Classification (SC), Henry E. Bliss' Bibliographic Classification (BC), and S. R. Ranganathan's Colon Classification (CC) also are standard classification systems, but they are less commonly used compared to aforementioned three systems. All these systems are easy to use and convenient for most general collection libraries. However, these systems are not adequate for some special collections. Libraries with rich collections on Islam also face problems while using these systems, although such libraries often use expansions in the original systems for their collections. This paper examines this problem and presents a potential optimal solution. The author collected data, using a semistructured interview technique, from a representative sample of thirty libraries in eight countries with strong collections in Islam. These data were analyzed employing qualitative methods.

Haroon Idrees (h.haroonidrees@gmail .com) is Senior Librarian, Islamic Research Institute, International Islamic University, Islamabad, Pakistan, and a PhD candidate at the Berlin School of Library and Information Science, Humboldt University of Berlin.

Submitted October 14, 2011; returned with request for revision October 14 2011; revised and resubmitted January 1, 2012; reviewed and accepted for publication February 18, 2012.

The author is thankful and presents his compliments to Professor Michael Seadle for his special support, for his guidance, and for reading the text for improvements.
Dewey Decimal Classification (DDC), Charles Ammi Cutter's Expansive Classification (EC), James Duff Brown's Subject Classification (SC), U.S. Library of Congress Classification (LCC), Universal Decimal Classification (UDC), Henry E. Bliss's Bibliographic Classification (BC), and S. R. Ranganathan's Colon Classification (CC) are internationally known standard classification systems. However, DDC, LCC and UDC are more widely used around the globe. These systems have served their purpose adequately in most disciplines and areas of knowledge. Nevertheless, some grey areas lack proper place and enumeration in these "fit-for-all" standard classification systems. Islamic knowledge is one area that has not been properly addressed by these systems. Hence the libraries that have developed extensive collections on Islam face the problem of organizing their collections while using these systems. This paper examines this problem and presents a potential solution. The author collected empirical data from thirty practicing librarians serving in libraries that have rich collections on Islam 
from eight countries (Pakistan, India, Malaysia, Iran, Saudi Arabia, Egypt, the United Kingdom, and the United States) using the semistructured interview technique. The author then analyzed the data to get a picture of current practices and challenges.

\section{Problem Statement}

Libraries that have developed extensive collections on Islamic knowledge face problems organizing their collections while applying the commonly used classification systems. The reason behind this problem is that the standard library classification systems do not provide sufficient place, proper enumeration, and sufficient expansion for resources on Islam. In response, such libraries have adopted incoherent, inconsistent, and nonuniform practices. These practices often employ locally developed nonstandard systems, develop expansions in given places in standard classification systems, and devise expansions using alternative place (notations) of the standard systems.

This paper is intended to address the following objectives:

1. To draw an accurate picture of the classification problems faced in the organization of Islamic knowledge and materials in the libraries that have reasonably good collections on Islam.

2. To know what local classification practices to overcome the problem are in use in these libraries.

3. To discover the satisfaction level of the libraries with their presently adopted classification systems.

4. To gather opinions about potential solutions to the problem from librarians in these libraries.

5. To suggest the optimal solution of the problem.

\section{Understanding the Context}

\section{Expansion of Knowledge and Literature Being Published on Islam}

Seeking, documenting, and preserving knowledge have deep roots in Muslim history. This can be seen in prepressera libraries developed by Muslim scholars and dynasties. Examples of such libraries include the library Al-Sahib Ibn 'Abbād during the fourth century of Islamic calendar (tenth century AD, Iran), which held a collection of 6,200 books with a ten-volume catalog. Al-'Aziz Fatimid (tenth century AD, Egypt) had a collection of 1.6 million volumes in his library. ${ }^{1}$ The historic Dar al-Hikmah library during the Abbasid caliph Ma'mun al-Rasheed era (ninth century AD, Iraq), Khazainulqusoor during the Fatimid period with 1.6 million books, and Hakam II's library with 400,000 books in tenth-century Spain are remarkable examples. This trend carried on during the Muslim rule in different parts of the world throughout history. ${ }^{2}$

Islamic studies continue as a vibrant field, evidenced in the volume of currently available publications. The author searched Amazon's online catalog (www.amazon.com) (using "books on Islam" as the search phrase) in April 2010 and found 17,726 titles on Islam published since 2000. Breakdown of this search result discovered the following:

- Titles published 2001-2: 2,897

- Titles published 2003-4: 3,515

- Titles published 2005-6: 3,361

- Titles published 2007-8: 4,050

- Titles published 2009 to date: 1,286.

The same search carried out in December 2011 resulted in 21,292 titles, an increase of 3,566 titles despite the possibility that a number of titles available in the previous search could be out of stock. Another search, conducted at the same time to verify this fact with a parameter of available titles published on Islam since April 2010, resulted in 5,004 titles. This shows a continued growth in publications on Islam. Dar Al-Kotob Al-Ilmiyah, a book publisher in Beirut, Lebanon had more than 4,400 titles available on more than one hundred main topics of Islam, in the 2009 catalog. ${ }^{3}$ The same publisher's 2011 catalog shows 5,394 titles available on Islam. ${ }^{4}$ A search using the term "books on Islam" in the Barnes and Noble (www.barnesandnoble.com) online cata$\log$ retrieved 24,307 titles available. A wide range of publications on a variety of Islamic subjects are available from local publishers in Muslim countries, although data of this output is not as easily available as that reported here.

\section{Classification of Islamic Literature}

According to Riazuddin, the devisors of all standard classification systems were from western parts of the world, except Ranganathan, who was from India but was not a Muslim. ${ }^{5}$ The environment of the devisors and their interests were the probable reasons that all these systems lacked attention to eastern areas of knowledge, especially Islam in the class of religions. DDC, which is the most popular standard classification system in the libraries of the east, provided only one of one thousand notations in the third summary. This was quite insufficient. Subsequently, many expansions were made in DDC to provide adequate placement for collections on Islam. These expansions were made either within the given space (i.e., notation 297) or alternatively utilizing the notations that were originally provided for Christianity.

Qaisar also mentioned the deficiencies of DDC regarding the class of religion. ${ }^{6}$ He proposed a reasonable amount of expansions in notation 297 for Islam in the sixteenth 
edition of DDC to cater the collections on Islam. Khurshid commented on the efforts made by Shafi for the expansion in DDC class for Islam. ${ }^{7}$ The summary of classes, along with subclasses devised by Shafi, is included in Khurshid's book. These recommendations were sent for the incorporation in the eighteenth edition of DDC, but were not added.

Sardar devised a classification system for Islam. ${ }^{8}$ Sardar's two objectives were encouraging a debate on the need for contemporary classification schemes on Islam and presenting a model for consideration and criticism. He invented a scheme comprising four major parts: (1) pre-main class; (2) main class; (3) post-main class; and (4) auxiliary schedules. Main classes have been denoted by capital letters, and small letters have been used for subclasses.

Chishti presented a historical review of classification in relation to Islamic materials, referencing the works of Farabi, Kawarzami, Ikhwan-Al-Safa, Ibn Sena, Ibn Hazam, Ibn Abdul Birr, Raghib Asfahani, Ghazali, Ibn Al-Nadeem and Ibn Abi Al-Rabie as the earliest efforts to classify Islamic knowledge. ${ }^{9}$ Chisti also described Razi's system with sixty main classes and many subclasses. According to Chishti, the theory and practice of classification developed historically beginning with knowledge classification, moving to bibliographic classification, then book classification, and finally utility classification.

Several individuals have developed classification systems focusing on Islamic works. A classification scheme for the oriental languages collection on Islam in the Punjab University Library in Lahore, India, was developed by Labhu Ram. ${ }^{10}$ In this scheme, "Ar" for Arabic, "P" for Persian, and "U" for Urdu collections have been used as notation prefixes. Bajwa, in his master's thesis, described contributions in the field of knowledge classification made by four ancient Muslim scholars: Al-Farabi, Ibn Al-Nadeem, Ibn Khuldun, and Tashkubrizada. ${ }^{11}$ Gacek, head of the Islamic Studies Library at McGill University, described the classification system developed by Wilfred Cantwell Smith, the founder of the institute, explaining that

the Smith classification system was developed by Prof. Smith, the first founder of the Institute. The system has not been used since 1982. It was abandoned in favor of the Library of Congress Classification. It is entirely on Islam (in its broad sense) and is divided into four main classes: A. Reference works; B. Extra-Islamic subjects; C. Classical Islam (until about $1800 \mathrm{AD}$ ); and M. Modern Islamic world (from about 1800 AD). ${ }^{12}$

A project of King Abdul Aziz University, Saudi Arabia, translated DDC into Arabic, with some amendments and expansions. ${ }^{13}$ The class of religion (200) was the core of this project. Hassan translated DDC into Urdu with some additions in the class of religion for Islam. ${ }^{14}$ Shaniti of Egypt translated the abridged edition of DDC into Arabic and expanded the Islamic topics using DDC classes 210-60 for Islam. ${ }^{15}$

The LC revised its class of $\mathrm{K}$ (Law) in 2002. ${ }^{16}$ An expanded class of KBP has been specified for Islamic law. The International Islamic University of Malaysia (IIUM) adapted this expansion in LCC to cover the areas of Islamic law more granularly. ${ }^{17}$ Notations KBP140-58 have been used for this purpose and cover more than 380 topics and subtopics of Islamic law. This expansion can be extremely helpful if an independent classification scheme is developed for Islam to deal with Islamic law. Usmani and Sabzwari mentioned shortcomings of standard systems and emphasized the need for a standard classification system for Islam. ${ }^{18}$

Quaid-e-Azam Library, in Lahore, Pakistan, developed an expansion with some alterations in the structure of DDC, nineteenth edition, using 220-80, seven classes for Islam. ${ }^{19}$ The Islamic Research Institute, in Islamabad, Pakistan, has devised an local scheme, covering 152 subjects. ${ }^{20} \mathrm{~A}$ list of subjects followed by Arabic numerals in ascending order has been made, and every book of a particular subject that arrives in the library is given the next serial number of the subject. Soltani has mentioned translations and expansions made in DDC and Library of Congress Classification (LCC) in Arab countries and Iran. ${ }^{21}$ These expansions were sent to DDC and LCC for incorporation. Unfortunately, the expansions could not be incorporated into either scheme, despite being appreciated by DDC and LCC teams.

The Indian Institute of Islamic Studies, New Delhi, developed a classification system based on UDC. ${ }^{22}$ Hundreds of topics and aspects of Islamic knowledge and literature were included in this scheme, which uses mixed notation. "IS" (for Islam) is used as a prefix in the notation. Usmani and Qudsi revealed that Shafi played a vital and leading role in developing an appropriate classification system for Islam, covering all gaps in the standard DDC system. ${ }^{23}$ According to Fatima, the central library of Karachi (Pakistan) University was using Shafi expansions for their collection on Islam. ${ }^{24}$

Riazuddin compiled an extension plan in the DDC for Islam within original notation designated by Dewey (i.e., 297). ${ }^{25}$ Because this was only an extension to one number, its scope is very limited and problems like lengthy notations and congestion are present in these extensions. Gondal devised a classification scheme for Islam, which used by the libraries of the Mosques Department of Punjab University's Quran Academy (Lahore, Pakistan), and partially in the Punjab University Central Library. ${ }^{26}$ Eraqi worked on an expansion of DDC eighteenth edition's class for Islam (i.e., 297). ${ }^{27}$ The Tehran Book Processing Centre also devised an expansion in DDC. ${ }^{28}$ These two expansions are similar except that the first is in Persian and the second in English. Standard 
subdivisions have been provided with every class. Sabzwari devised an expansion for Islam using the DDC eighteenth edition classes $210-60 .{ }^{29}$ Khan devised an expansion in DDC twenty-first edition for the life, family, and companions of Muhammad (PBUH) using notations 297.63 and 297.64. ${ }^{30}$

According to S. S. H. Rizwi and S. J. A. Rizwi, Dickinson's expansions in DDC made for Punjab University Library in 1916 are considered the oldest expansions of DDC, followed by Indian Library Association, Yousufuddin Ahmad, and Molvi Shafi expansions. ${ }^{31}$ Altaf Shaukat also devised an expansion for Islam in DDC, which is similar to the Shafi expansion. ${ }^{32}$ Rizwi noted the extensive collections in the libraries on Islam and inadequate classification schemes to classify them. ${ }^{33}$ He reviewed the Colon classification, Bliss classification, DDC, and LCC, and found them insufficient. Rizwi devised a schedule of Islamic topics, without provision of any notation, based on Shafi's expansion with some amendments and additions.

Aaedi compiled an Arabic translation of abridged edition of DDC 21 with some expansions in the classes of Arabic language, literature, geography, and history, and the Islam religion. It is similar to the one made by King Abdul Aziz University in $1977 .{ }^{34}$ Idrees and Mahmood determined that DDC is the only standard classification system being used in Pakistani libraries that have rich collections on Islam. ${ }^{35}$ According to Sabzwari, the situation is the same in other Muslim countries. ${ }^{36}$

The multitude of approaches to classifying Islamic materials described above make clear that many have sought to address the problems. A brief comparison between three local expansions (developed by the Quaid-e-Azem Library, Muhammad Shafi, and S. Mahmood Hasan Qaisar) of DDC along with a picture of historical developments in different editions of DDC regarding Islam is presented in figure 1. The figure shows that the early editions of DDC until the sixteenth edition provided only one notation for Islam without its further extensions. A noteworthy point is that the term "Mohammedanism" was used as the heading instead of "Islam" until the fifteenth edition. The later editions used the term "Islam" along with its further extension, standard subdivisions, and number-building options. The twenty-first and twenty-second editions of DDC included some drastic expansions in the notation for Islam. Additional revisions and expansions have been made in the twenty-third edition, in which Hadith (statements or actions of Muhammad) has been relocated to 297.125 from 297.124. Some topics for future development are under discussion on 025.431: The Dewey Blog (http://ddc.typepad.com), which is edited by Jonathan Furner, assistant editor of DDC. Nevertheless, the independently developed local expansions made to the earlier editions of DDC still provide more space and options for Islam compared with the DDC twenty-first, twenty-second, and twenty-third editions.
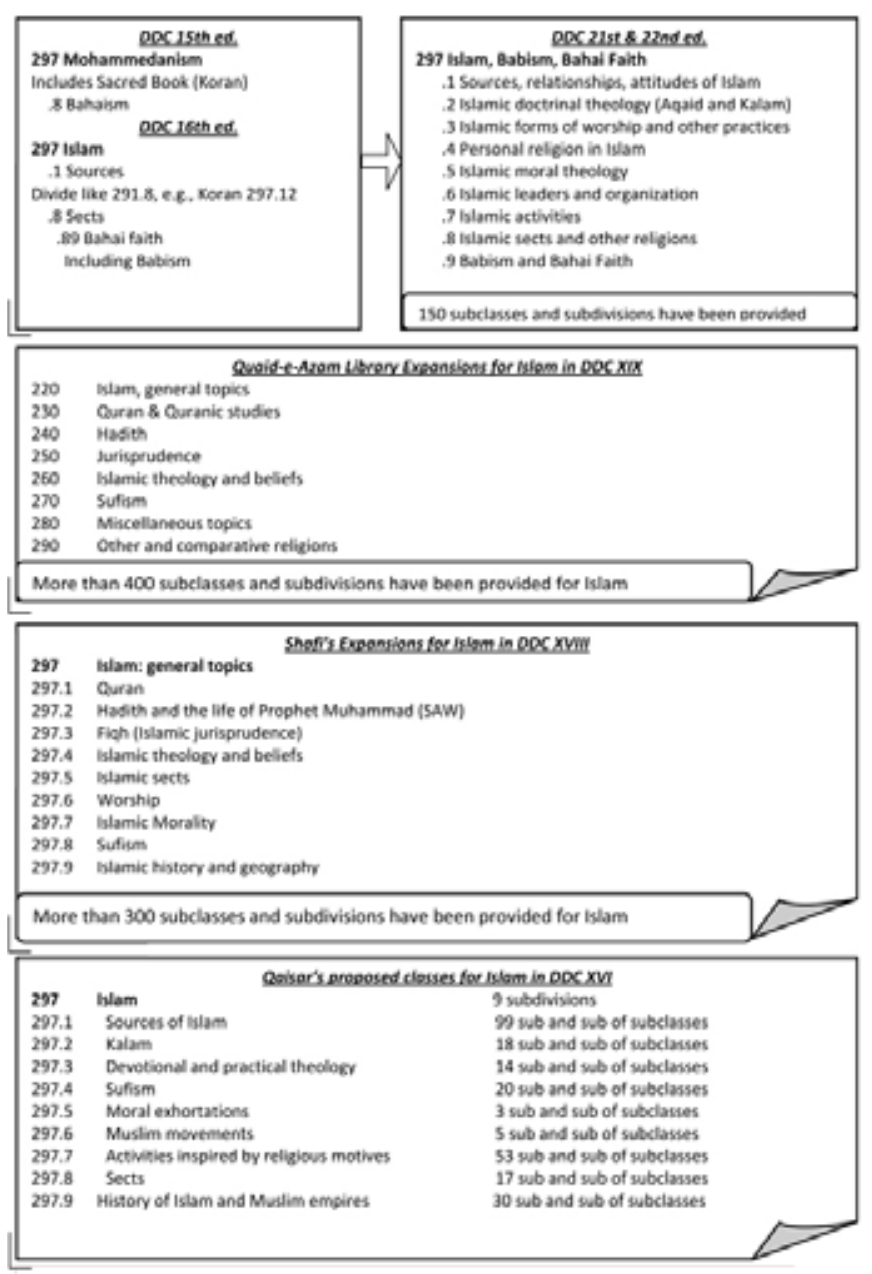

Source: Haroon idrees, "Classification of Library Materials on islam: A Literature Survey." OCLC Systems \& Service 27, no. 2 (2011): 138.

Figure 1. A Brief Comparison of DDC and Local Expansions for Treatment of Islam

\section{Literature Review}

The professional literature shows dissatisfaction with the classification of Islamic literature, not only in the Indian subcontinent and Muslim countries, but also in other countries. The Smith classification at McGill University was developed to address this problem. ${ }^{37}$ Following is a brief literature review. For a detailed review, see the author's "Classification of Library Materials on Islam: A Literature Survey." ${ }^{38}$

Many authors have criticized standard classification schemes for their shortcomings in the treatment of eastern and oriental topics and for their western bias. ${ }^{39}$ These three systems are most frequently discussed because they have provided some reasonable space for classification of Islamic literature. The authors have criticized the schemes for their western bias, vested interest, lack of space for eastern knowledge (especially Islamic knowledge), and improper 
enumeration and hierarchy of the topics. Other systems, e.g., CC, EC and BC, have not been discussed frequently because they have provided such minimal options and are not significant enough to discuss.

Mitchell, editor in-chief of DDC, admitted the presence of Christian bias and improper place for Islam in DDC in a presentation at the 2003 International Federation of Library Associations and Institutions (IFLA) general conference:

In DDC 22, we have completed the two-edition plan that was initiated in DDC 21 to reduce Christian bias in the 200 Religion schedule. In DDC 21, we moved comprehensive works on Christianity from 200 to 230 , and relocated the standard subdivisions for Christianity from 201209 to specific numbers in 230-270. We integrated the standard subdivisions of comparative religion with those for religion in general in 200.1-.9. We also revised and expanded the schedules for two major religions, 296 Judaism and 297 Islam. $^{40}$

\section{Research Methods}

The author first reviewed the literature on the problem of effectively handling Islamic literature and its relevant aspects to learn the intellectual and practical background and implications of the problem. Standard classification systems and schemes also were consulted for guidance.

The author then conducted interviews to collect data. The problem in hand is of a social nature, and not many quantifiable variables were involved in this study. The problem also involved exploration of subjective aspects of human experience. People's perception of the potential solution to the problem also was sought. Therefore the author opted to use qualitative methods for this study following the guidance of Powell and Connaway. ${ }^{41}$ The author selected the technique of interviewing to collect data, keeping in mind the benefits and suitability identified by Gorman and Clayton, i.e., immediacy, mutual exploration, investigation of causation, personal contact, and speed. ${ }^{42}$ Three types of interview are possible: structured, semistructured, and nonstructured. Semistructured interviewing was selected. The author interviewed 30 library practitioners serving in libraries in Pakistan, India, Malaysia, Saudi Arabia, the United Kingdom, and the United States, with rich collections on Islam. These interviews were conducted through direct meetings, interactive online sessions, telephone conversations, and audio/video conferences. The interview structure used to collect data appears in the appendix. This study does not include automatic classification solutions because the main portion of the relevant population is not using such solutions.

\section{Results and Discussion}

\section{Libraries Investigated}

The 30 libraries from which the data were collected represent almost all types of libraries, i.e., academic, special, public, and national libraries. A majority (20) are academic libraries at universities. Five are special libraries (court, bank, and specific research institutes), 2 are public libraries, and 3 are national libraries. Table 1 shows the libraries in this study by type and location.

The participant libraries hold collections of varying size. The collections in the sampled libraries ranged from 15,000 to 2,065,000 volumes. Four libraries have collections of fewer than 50,000 volumes, all being special collection libraries focusing mainly on Islam. Five libraries have collections between 100,000 and 200,000; 11 libraries have collections between 200,001 and 500,000. Three libraries hold collections between 500,001 and 1,000,000. Seven libraries have collections of more than 1,000,000 volumes. Frequency distribution of libraries by their collection has been displayed in table 2.

Collections on Islam in these libraries range from 15,000 to 400,000 volumes. Nearly 37 percent (11 respondents) have Islamic collections in excess of 100,000. Seven libraries have collections of between 15,000 to 20,000 volumes. Eight libraries hold collections of 20,001 to 50,000 . Four libraries have collections of between 50,001 to 100,000 , while 9 libraries have collections of between 100,001 and 200,000 volumes. Only 2 responding libraries contain collections of more than 200,000 volumes on Islam. The composite total collection of all 30 libraries approaches the figure of $15,144,000$ with an average of 504,800 volumes per library, whereas the composite total collection on Islam is $2,543,000$ - an average of 84,767 volumes per library.

Table 1. Types of Libraries by Country

\begin{tabular}{lcccc}
\hline & \multicolumn{4}{c}{ Type of Library } \\
Country & National & Public & Academic & Special \\
\hline Pakistan & 1 & 1 & 4 & 3 \\
\hline S. Arabia & -- & -- & 5 & -- \\
\hline Iran & 1 & 1 & 2 & 1 \\
\hline India & -- & -- & 3 & -- \\
\hline Egypt & 1 & -- & 2 & -- \\
\hline Malaysia & -- & -- & 2 & -- \\
\hline U.K. & -- & -- & 1 & 1 \\
\hline U.S. & -- & -- & 1 & -- \\
\hline Total & 3 & 2 & 20 & 5 \\
\hline
\end{tabular}




\begin{tabular}{lcc} 
Table 2. Size of Library Collections & \\
\hline Volumes Held & Libraries & Percentage \\
$<50,000$ & 4 & 13.3 \\
$100,000-200,000$ & 5 & 16.7 \\
$200,001-500,000$ & 11 & 36.7 \\
$500,001-1,000,000$ & 3 & 10 \\
$>1,000,000$ & 7 & 23.3 \\
Total & 30 & 100.00 \\
\hline
\end{tabular}

\section{Librarians Included in Sample}

The author contacted one person (either the chief librarian, the individual responsible for technical services, or the section head of Islamic collections) at each library for the interviews. The author sought to interview the most appropriate people who are aware of and in touch with the problem in hand. Five out of 30 interviewed subjects are working as chief librarians of their libraries, and the other 25 are working as librarians. The academic qualifications of the 30 interviewed library personnel are as follows:

- Nine (30 percent) have $\mathrm{PhD}$ degrees.

- Nineteen (63.4 percent) have masters degrees.

- One (3.3 percent) has a bachelor of library science (BLS) and a post-BLS diploma.

- One (3.3 percent) has a BLS degree.

\section{Classification Systems in Use}

No uniform practice regarding the usage of classification systems for materials on Islam was found among the libraries in this study. A significant majority ( 25 or 83.3 percent) use multiple systems, i.e., standard systems for general collections and local systems or expansions made in standard systems for materials on Islam. This is because the standard systems are convenient for general topics, but they do not optimally fulfill the classification needs of materials on Islam. Of the 5 libraries that use single standard system, 4 are using DDC, while 1 is using LCC. The 25 libraries that use multiple classification systems break down in the following manner:

- 18 use DDC and local expansions in DDC

- 3 use LCC and local expansions in LCC

- 1 uses LCC and DDC, plus local expansions in LCC and DDC

- 1 uses DDC and local expansions in DDC, plus an independent local scheme

- 1 uses DDC and an independent local scheme

- 1 uses LCC and an independent local scheme
Table 3. Size of Library Collections on Islam

\begin{tabular}{lcc}
\hline Volumes Held & Libraries & Percentage \\
$15,000-20,000$ & 7 & 23.3 \\
$20,001-50,000$ & 8 & 26.7 \\
$50,0001-100,000$ & 4 & 13.3 \\
$100,001-200,000$ & 9 & 30.0 \\
$>200,000$ & 2 & 6.7 \\
Total & 30 & 100.00 \\
\hline
\end{tabular}

- 20 are using 8 different expansions made in DDC

- 4 are using 4 different expansions made in LCC

- 1 is using 1 expansion made in UDC

Three different independent local schemes are being used for Islam. Five groups of libraries were using the same classification systems and their expansions. One group consisted of 5 libraries and the other 4 groups consisted of 3 libraries each. Only 2 of these 5 groups had coordination between the members. Figure 2 presents a summary of the classification systems in use by the sampled libraries.

\section{Libraries' Satisfaction with Classification Systems}

Interviewees were asked whether the classification systems in use were suitable for the organization of Islamic collection being acquired in the libraries and if the libraries were satisfied. Libraries' level of satisfaction has been classified into three main categories: satisfied (the systems are optimally fulfilling the requirements), partially satisfied (the requirements are being fulfilled so far, but, for certain materials, systems is use do not have the options needed, and unsatisfied (the available systems do not fulfil the requirements and present numerous problems and shortcomings when classifying materials on Islam). Only 1 library was satisfied with standard classification systems and 1 was partially satisfied. None of the 3 users of independent local schemes on Islam were satisfied; 2 were partially satisfied. Two out of 23 libraries using local expansions were satisfied and 17 were partially satisfied. Figure 3 shows the level of satisfaction with classification systems currently in use.

\section{Problems Being Faced by the Libraries}

The participants were asked about the problems they had been facing and that were causing their dissatisfaction. They identified the following specific problems or shortcomings in the available standard combined with local systems:

- Allocated space for Islam in standard classification systems is too limited to cover all Islamic subjects 


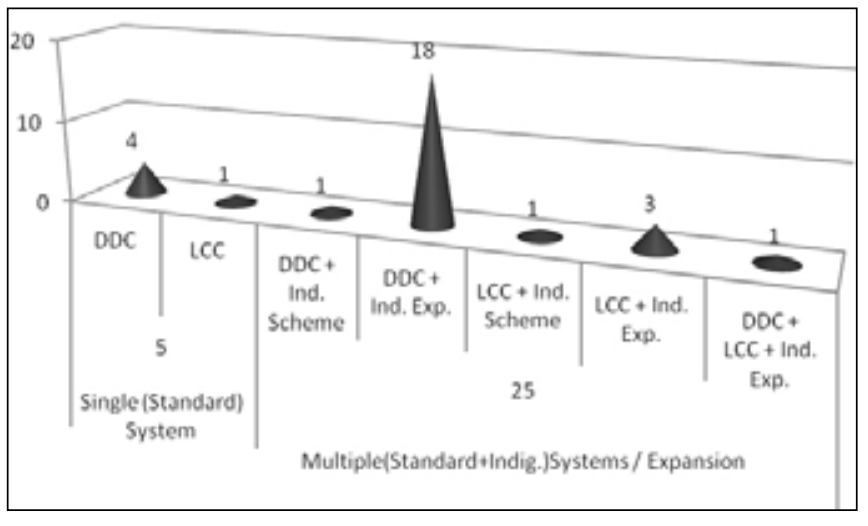

Figure 2. A Summary of the Classification Systems in Use

minutely (27 participants)

- New and emerging topics are not found in local expansions of standard systems (10 participants)

- Standard systems do not comprehensively cover Islamic knowledge, so new and emerging topics are not found there ( 2 participants)

Additionally, the following problems were identified by 1 participant each:

- No standard was followed in developing the local system being used in his or her library, with only a list of subject terms developed.

- Ineffective and noncomprehensive classification systems are creating a result in form of improper organization and inefficient browsing of library materials.

- No uniformity exists with other libraries with similar collections because different and dissimilar classification systems are being used.

- No coordination with other similar libraries is present.

- The types and variety of materials being published on Islam exceed the provisions in systems.

\section{Solution to the Problems}

The researcher asked participants for their suggestions for an optimal solution to the problem in hand. A majority (22) suggested developing a new, independent, and comprehensive classification system for materials on Islam. Two suggested amendments and expansions in standard classification systems. Two suggested both amendments and expansions in standard classification systems and a new, independent, and comprehensive classification system for materials on Islam. They further suggested that the first approach would be suitable for libraries having small or medium-size collections on Islam, and the second could be used by the libraries having larger collections on Islam.

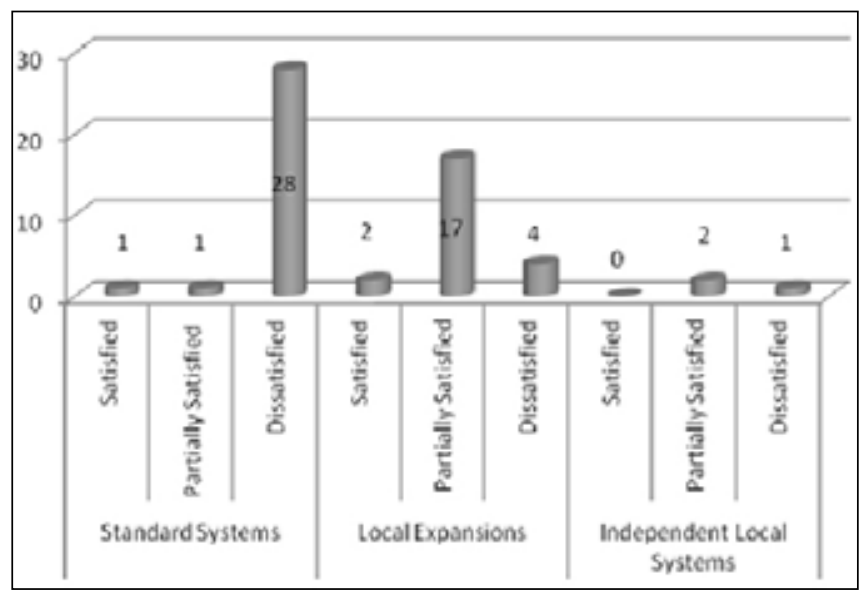

Figure 3. Libraries' Level of Satisfaction with Current Systems

Three librarians suggested amendments and expansions in standard classification systems as their first preference if it could be incorporated in the original systems. They mentioned a new, independent, and comprehensive classification system for materials on Islam as their second priority if the amendments and expansions were not incorporated in the original systems. Finally, 1 proposed a new, independent, and comprehensive classification system for materials on Islam as the first priority and amendments and expansions in standard classification systems as a second preference.

\section{Amendments and Expansions in Standard Systems}

The 8 participants who suggested amendments and expansions to standard systems differed in their view of how they should be made. Four thought that expansions should be made within the existing system (e.g., an extension in 297 in DDC). The other 4 thought that notations specified for Christianity should be used for Islam so that the base may be broadened. Three believed that the owners of standard systems would accept these expansions and incorporate them in their system. The remaining 5 thought that the standard systems would not accept them; nevertheless, participants felt that amendments and expansions should be made and used locally.

The same 8 participants were asked who should work on amendments and expansions in standard classification systems. Some, who suggested a new and independent system, also expressed their opinions. Three participants suggested that this should be done by professional associations. Two suggested specifically that IFLA should do the work. Two suggested that library and information science professionals and scholars of Islamic studies should collaborate for this purpose. Two suggested placing this work under the 
umbrella of the Organisation of Islamic Conference (OIC) (www.oic-oci.org). One proposed that professional associations, along with academia, should take the responsibility, and 1 suggested that the work should be done by an individual strongly backed up by an institution.

\section{A New, Independent, and Comprehensive System for Islam}

Participants generally shared the same views on a new, independent, and comprehensive system for Islamic materials. Twenty-eight agreed that the variety and depth in Islamic topics and the volume of published literature indicate a real need for developing an independent and comprehensive classification system for materials on Islam. Twentyeight also agreed that developing an independent and comprehensive classification system exclusively for Islamic materials was technically possible. The term "technically" did not mean technologically, but instead referred to the classification techniques, methods, and approach to develop a scheme for a specific area of knowledge. Twenty-seven agreed that guidance for developing an independent system for Islam was available both previously developed standard and local classification systems and the published literature on their shortcomings.

Implementing a New, Independent, and Comprehensive System for Islam

Developing a new, independent, and comprehensive classification system specifically for Islam is one side of the problem but, practically, its implementation in the libraries is the other side: it has its own complexities. The libraries have materials on topics other than Islam, which would compel them to use some other (standard) system for these materials, even if they use an independent system for Islamic collections. Having multiple systems of classification has its own repercussions. It affects uniformity of the system and complicates training of both staff and library users. If a new system were to be implemented, it would create a problem of reclassification of materials already in the collection. All these involve time and cost. Thus participants were asked about implementing a new system. Two-thirds of the respondents (21) stated that implementing such a system would be possible because their libraries had already been practicing multiple classification systems for collections of different natures. Therefore they would adopt a new system for materials on Islam and could use the standard system for other materials, provided the new system meets the requirements of collections on Islam. Four participants mentioned that reclassification presented a serious issue, but the solution could be found after brainstorming. One participant said that the solution

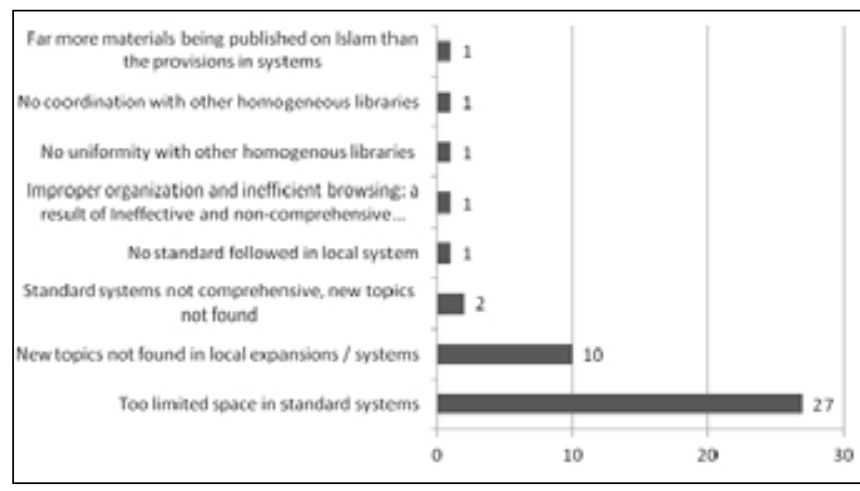

Figure 4. Problems being Faced and Mentioned by Libraries

could be found after the new scheme was published, disseminated, and discussed widely. Another participant felt that implementing a new system would be very difficult, although a new, comprehensive, and independent system is very attractive. Finally, 1 participant noted the time and cost are involved in the implementation of a new and independent classification system and stressed the need to think and rethink before reaching any decision.

\section{Nature and Format of New Classification System}

Twenty-six of the 28 respondents who supported a new independent classification system for Islam suggested developing an enumerative classification system under the precoordination approach. Only 2 participants were in favor of faceted classification with a post coordination approach. A strong argument in favor of an enumerative system is consistency. If the notation and call number building are left to individuals and their own perspective in each library, the result will remain fragmented and discordant.

Nevertheless, respondents expressed some differences of opinion regarding the format of notation. Some were in favor of having a pure notation, and some supported a mixed notation. Fourteen suggested a pure notation constructed by Arabic numerals; of these, 10 were in the favor of decimal notation. Three suggested a notation that should represent the general-to-specific hierarchy, 6 supported a mixed notation, and 5 were indifferent to the structure or formation of notation. They emphasized the need for a proper enumeration and expansion of the subjects and topics, but any notation (whether a pure, mixed, numeric, alpha-numeric, or decimal) used for their representation would be acceptable.

\section{Suggestions for Action}

The empirical data taken through the interviews shows a gloomy situation regarding the classification practices and 
usage of classification systems to organize the Islamic knowledge in the libraries that have rich collections on Islam. Neither the standard classification systems nor local expansions or schemes are fulfilling the purpose. The reasons behind this problem could be the background of the devisers of the standard classification systems. Perhaps they were unaware of the length and breadth of the expansion of Islamic knowledge and the variety of topics and materials being produced. Second, perhaps they did realize that their systems could spread around the globe and that a range of the libraries throughout the world would be using these schemes at some point. Their personal interest and biases also may be among the reasons. Once they formed the basic structure of their schemes, drastic changes in the design, structure, and format of these systems was very difficult. In response to these problems, different practices have been adopted. Sometimes libraries developed their own systems without following or developing any standards. Some libraries developed expansions in the standard systems. Efforts were made to get these expansions formally incorporated in the original schemes, but such efforts have not yet succeeded. Libraries have taken very different approaches in the expansions of even the same standard systems and no uniformity is found. Thus the same kind of knowledge is organized differently at different places.

The collected data suggest the following considerations for addressing the problem:

- A majority of the participants believe that developing a new, independent, and comprehensive system is a real need of libraries that have rich collections on Islam. "Comprehensive" means a system that covers all the relevant and potential aspects of Islamic knowledge and the materials being published on associated topics.

- Developing such a system is a viable project because guidance is available from standard systems, local systems, and expansions.

- This system should be an enumerative system with opportunity and instructions for notation and callnumber building by combining different concepts of overlapping topics and themes.

- This system should be sent to the relevant libraries that have developed very rich collections on Islam, scholars of library and information science, and Islamic studies scholars for validation and verification.

- The input of the libraries and scholars should be incorporated and suggested changes should be made in the system.

- This system should be presented at international conferences, and feedback should be taken and incorporated.
- This system should be marketed and adopted by the libraries.

- Finally, some organization, federation, or association should adopt this system and make the necessary arrangements for updating the system through the formation of editorial boards.

- Implementation of such a system needs special attention. Implementing such a system along with other systems will not be an easy task. Thus consultation and coordination with relevant libraries is essential.

- While developing the new system, two points should be kept in mind. First, a notation should be chosen that will not contradict or conflict with the notations of standard systems, especially DDC and LCC, so that the compatibility with these systems can be achieved. Second, every effort should be made to integrate the new system with DDC and LCC.

\section{Conclusion}

The author conducted this study with the hypothesis that libraries with rich collections on Islam were facing problems organizing these collections. These libraries had opted for different standard classification systems and their expansions, but they were not satisfied with available choices. Previously developed expansions were developed on the basis provided by the enumeration and design of structure and hierarchy of standard systems, which is different from the hierarchy of Islamic knowledge perceived by Islamic studies. The author's hypothesis was based on the survey of literature and supported by empirical data from a very limited population. The author conducted an empirical study based on a wider population to verify this hypothesis. The collected data supported the hypothesis. Most of the libraries were using different standard classification systems along with expansions. Only a few libraries were using nonstandard systems. The majority of the respondents in this study are not satisfied with the available options and identified a need to develop a new, independent, comprehensive, and properly enumerated classification system for Islam. This need was based on the variety, depth, and expansion capacity in Islamic topics and the volume of literature being produced on Islam.

Most of the sampled population suggested developing an enumerative classification system with a precoordination approach, maximum possible coverage of all Islamic topics, and number-building options. Most felt that implementing such a system for Islam while using a standard system for other library collections was possible because they already had such an experience. Therefore the author believes that a new, independent, and comprehensive classification system should be developed for the libraries that have rich 
collections on Islam. All expansions in standard systems, especially the KBP expansions in LCC for Islamic law adapted by the International Islamic University of Malaysia and expansion in UDC done by the Indian Institute of Islamic Studies, can be very helpful in developing a new classification system for Islam.

\section{References}

1. Abdul Latif Dohaish, "Mosque and School Libraries in Early Islamic Period," [text in Urdu] Pakistan Library Bulletin 17, no. 2 (1986): 1-19.

2. Saad Siddiqui, Our Religious Libraries [text in Urdu] (Lahore, Pakistan: Quaid-e-Azam Library, 1986): 36.

3. Dar Al-Kotob Al-Ilmiyah, "DKI Catalogue," 2009, www.al -ilmiyah.com (accessed June 7, 2010).

4. Dar Al-Kotob Al-Ilmiyah, "DKI Catalogue," 2011, www.al -ilmiyah.com/dki_cat2011.htm (accessed Dec. 18, 2011).

5. Syed Riazuddin, Classification (Islamabad, Pakistan: Muqtadara Qaumi Zuban, 1993).

6. S. Mahmood Hasan Qaisar, Islamic Sciences: Expansion of Dewey Decimal Classification ed. XVI, for Oriental Libraries (Aligarh, India: Institute of Islamic Studies Aligarh Muslim University, 1974).

7. Anis Khurshid, Shafi Dewey Decimal Expansions for Islam: An Introduction [text in Urdu] (Karachi, Pakistan: Royal Book Company, 1977).

8. Ziauddin Sardar, Islam: Outline of a Classification Scheme (London: C. Bingley, 1979).

9. Abdul Haleem Chishti, Islamic Libraries from 2nd Century Hijri Year 133 to Seventh Century Hijri Year 656 [text in Urdu] (unpublished doctoral dissertation, Karachi [Pakistan] University, 1978): 510-55.

10. Labbu Ram, Punjab University Library Classification Scheme (unpublished).

11. R. A. Bajwa, A Select Study of Classification Systems Devised by Muslim Scholars (unpublished masters dissertation, Karachi [Pakistan] University, 1969).

12. Adam Gacek, personal communication to the author, March 2008.

13. King Abdul Aziz University, Al-Tasnif al-Ashri [text in Arabic] (Jeddah: King Abdul Azziz University, 1977).

14. Syed H. Hassan, Decimal Classification \& Library System [text in Urdu] (Lahore: West Pakistan Urdu Academy, 1973).

15. Mahmood Shaniti, Abridged Decimal Classification Scheme [text in Arabic] (unpublished doctoral dissertation, Cairo University, 1960).

16. Yushiana Mansor and Younis Ahmad Ismāīil al-Shawābikah, "Library of Congress Classification: Catalogers' Perceptions of the New Subclass KBP," Library Review 56, no. 2 (2007): $117-26$.

17. International Islamic University of Malaysia, Expansion on Islamic Law off LCC Scheme, (unpublished, 2006).

18. Muhammad Adil Usmani, "Classification System for Islamic Literature and Muslim Countries," Pakistan Library Bulletin 13, no. 2 (1982): i-vi; Ghaniul Akram Sabzwari, "Universal Islamic Classification," Pakistan Library Bulletin 13, no.
2 (1982): 1-20.

19. Quaid-e-Azam library, Classification Scheme for Islamic Materials, Literature, Regional Literature, Pakistan, etc. (unpublished, 1987).

20. Islamic Research Institute. Classification Scheme (unpublished, 1980).

21. Poori Soltani, "Translation and Expansion of Classification Systems in the Arab Countries and Iran" (presentation at 61st IFLA General Conference, Istanbul, Turkey, August 20-25, 1995), http://archive.ifla.org/IV/ifla61/61-solp.htm (accessed Dec. 23, 2011).

22. Indian Institute of Islamic Studies, Library Classification Schedule on Islam and Related Subjects (New Delhi: Indian Institute of Islamic Studies, 1974).

23. Muhammad Adil Usmani, "Haji Muhammad Shafi in Karachi University Library," Pakistan Library Bulletin 5, no.3-4 (1973): 15-21; Obaid Qudsi, "Haji Muhammad Shafi," [text in Urdu] Pakistan Library Bulletin 1, no. 4 (1969): 97-104.

24. Fatima, Nasim, "Dr. Mahmud Hussain Library, University of Karachi," [text in Urdu] Pakistan Library Bulletin 12, no. 2 (1981): 1-25.

25. Syed Riazuddin, Classification of Islamic Literature (Karachi, Pakistan: Royal Book Company, 2002).

26. Hafiz Mukhtar Gondal, Classification for Islam \& Islamic Studies [text in Urdu] (unpublished, 1999).

27. Ahmad Tahiri Eraqi, Dewey Decimal Classification: Islam [text in Persian] (Tehran: National Library of Iran, 1985).

28. Tehran Book Processing Centre, Dewey Decimal Classification and Relative Index: Islam (Tehran: Institute for Research \& Planning in Science and Education, 1975).

29. Ghaniul Akram Sabzwari, Classification: Eastern Philosophy, Islam, Alsunna Alsharqiya, Pakistan (Karachi, Pakistan: Library Promotion Bureau, 2007).

30. Sher Nowrooz Khan, "Expansion of DDC 21st Edition Number 297.63 for the Sirah," Pakistan Library \& Information Science Journal 35, no. 4 (Dec. 2004): 26-34.

31. Syed S. H. Rizwi, Library and its Administration [text in Urdu] (Mirreth: Rastugi and Co., 1940): 91-116; Syed J. A. Rizwi, "Classification Expansions," in Classification and Cataloguing [text in Urdu], ed. Anwarulhaq, 159-214 (Islamabad, Pakistan: Allama Iqbal Open University, 1996).

32. Altaf Shaukkat, Nizam-e-Kutub Khana [text in Urdu] (Lahore, Pakistan: Sheikh Ghulam Ali \& Sons, 1970).

33. Syed J. A. Rizwi, A Comparative Analysis of Classification of Islam [text in Urdu] (research report for partial fulfilment of masters degree, University of the Punjab, Lahore, Pakistan, 1975).

34. Muhammad A. Aaedi, Concise Decimal Classification for Small Libraries [text in Arabic] (Cairo: Academic Publisher, 1999).

35. Haroon Idrees and Khalid Mahmood, "Classification of Islamic Literature in Pakistani Libraries: A Survey," Library Review 59, no. 3 (2010): 149-64.

36. Ibid.

37. Wilfrid Cantwell Smith, Islamic Classification in Use at McGill University Islamic Studies Libraries, rev. ed. with explanatory notes (Montreal: McGill University Islamic Studies Libraries, 1979). 
38. Haroon Idrees, "Classification of Library Materials on Islam: A Literature Survey," OCLC Systems \& Services 27, no. 2 (2011): 124-45.

39. Asa Don Dickinson, The Punjab Library Primer (Lahore, Pakistan: University of the Punjab, 1916): 29-35; Rizwi, A Comparative Analysis of Classification of Islam; Anis Khurshid, "Developments in Cataloguing and Classification in Pakistan," in Cataloguing and Classification of Non-Western Material: Concerns, Issues and Practices, ed. M. M. Aman, 253-57 (Phoenix, Ariz.: Oryx, 1980); Lois Mai Chan, Cataloguing and Classification: An Introduction (New York: McGraw-Hill, 1981); David H. Elazar, "The Making of a Classification Scheme for Libraries of Judaica" (paper presented at the 66th IFLA Council and General Conference, Jerusalem, Israel, August 13-18, 2000), http://archive.ifla .org/IV/ifla66/papers/080-174e.htm (accessed Jan. 19, 2012); Vanda Broughton, "A New Classification for the Literature of Religion" (paper presented at the 66th IFLA Council and General Conference, Jerusalem, Israel, August 13-18, 2000), http://archive.ifla.org/IV/ifla66/papers/034-130e.htm (accessed Jan.19, 2012); Sabzwari, "Universal Islamic Classification"; Catherine. B. Morgan, "Cultural and Religious Problems in Dewey Decimal Classification," 1996, http://home
.usit/\%7Ecbmorgan/index.htm (accessed Nov. 23, 2007); Shiekh Ibrahim, Dewey's Classification Scheme: Criticism \& Suggestions (Karachi, Pakistan: Dr. Mahmood Hussain Library, Karachi University, 1982); Usmani, "Classification System for Islamic Literature and Muslim Countries”; Eraqi, Dewey Decimal Classification: Islam; Soltani, "Translation and Expansion of Classification Systems in the Arab Countries and Iran"; Muhammad Sadiq, "Classification of Islamic Literature," Gomal University Journal of Research 22 (2006): 122-28; M. U. Rehman, N. H. Nizami, and S. Shaikh, Super Classification System (Karachi, Pakistan: The Authors, 2003).

40. Joan S. Mitchell, "DDC22: An Introduction" (presentation at the World Library and Information Congress: 69th IFLA General Conference and Council, Berlin, Germany, August 1-9, 2003), http://archive.ifla.org/archive/IV/ifla69/ papers/121e-Mitchell.pdf (accessed Dec. 23, 2011).

41. Ronald R. Powell and Lynn Silipigni Connaway, Basic Research Methods for Librarians (London: Libraries Unlimited, 2004): 59.

42. Gary E. Gorman and Peter Clayton, Qualitative Research for Information Professional (London: Facet Publishing, 2005): $125-42$.

\section{Appendix. Proposed Interview Structure}

1. Interviewee name and position?

\section{Basic Information}

2. Qualification?

3. Name of library and parent organization?

4. Type of library? (academic, public, special, any other sector?)

5. Total library collection?

6. Collection on Islam?

\section{Core Interview Questions}

1. Which classification system is used in your library?

a. For general library collections?

b. For collections on Islam?

2. Is it a standard classification system* known at international level, or developed locally?

3. If locally developed, has it been developed in-house by your library or has another individual or group developed it? 3.1. Are any libraries also using this system? How many are they and do you have any coordination and collaboration among yourselves?

3.2. Is it serving the purpose of classification adequately regarding library collection on Islam?

3.3. If not serving the purpose adequately, what are the problems, shortcomings, or inadequacies that you are facing?

4. If you are using a standard classification system, is it serving the purpose of classification adequately regarding library collection on Islam?

4.1. If not serving the purpose adequately, what are the problems, shortcomings, or inadequacies that you are facing?

5 . What is the solution to these problems in your opinion?

6. Should amendments and expansions be made in existing standard classification systems or should some new, independent, and comprehensive system be devised for classification of materials on Islam?

6.1. If you recommend amendments/expansions in already existing standard classification systems, should there be expansions in originally allocated classes/notations in the systems or some other notations, e.g., originally allocated to Christianity or any other religion can be alternatively used for Islam? 
6.2. If amendments should be made in your opinion, who should take the responsibility to do this? Any library? Library school(s)? Professional associations? Some individual professional or a group of professionals?

6.3. Do you think that sufficient expansions can be successfully made and incorporated in the standard classification systems? Would the systems accept and incorporate these expansions?

7. If a new classification system to classify materials on Islam should be developed, is it technically** possible in your opinion?

7.1. Do you think that an independent classification system for Islam is a real need, given the variety, depth, and capacity in Islamic topics and the volume of literature being published?

7.2. Is literature for guidance available to develop an independent and comprehensive classification system for Islam?

7.3. If a new and comprehensive classification system for Islam is developed, how can it be implemented practically in the presence of materials in the library on topics other than Islam?

7.4. Should the new system be enumerative, where the maximum coverage to the subjects is provided under precoordinated approach or it should be faceted, where number building by the classifier is significantly involved?

7.5. What should be format of classification and notations?

8. Anything else in you would like to add?

${ }^{*}$ By standard classification system, we mean any of the internationally known and used systems, e.g., Dewey Decimal Classification (DDC); Charles Ammi Cutter Expansive Classification (EC); James Duff Brown's Subject Classification (SC); U.S. Library of Congress Classification (LCC); Universal Decimal Classification (UDC); Henry E. Bliss's Bibliographic Classification (BC); and S. R. Ranganathan's Colon Classification (CC).

${ }^{*}$ Technically includes the classification techniques, methods, and approach and not the information, communication, or any similar technology. 